University of Nebraska - Lincoln

DigitalCommons@University of Nebraska - Lincoln

\title{
DEVELOPMENT OF A QUALITY-ASSESSED AGRICHEMICAL DATABASE FOR MONITORING ANTHROPOGENIC IMPACTS ON GROUND-WATER QUALITY
}

\author{
Mary Exner Spalding \\ University of Nebraska-Lincoln, mspalding1@unl.edu \\ Roy F. Spalding \\ University of Nebraska - Lincoln, rspalding1@unl.edu \\ Dorothy M. Harrell \\ University of Nebraska - Lincoln, dharrell2@unl.edu
}

Follow this and additional works at: https://digitalcommons.unl.edu/natrespapers

Part of the Natural Resources and Conservation Commons

\footnotetext{
Exner Spalding, Mary; Spalding, Roy F.; and Harrell, Dorothy M., "DEVELOPMENT OF A QUALITY-ASSESSED AGRICHEMICAL DATABASE FOR MONITORING ANTHROPOGENIC IMPACTS ON GROUND-WATER QUALITY" (2005). Papers in Natural Resources. 324.

https://digitalcommons.unl.edu/natrespapers/324
}

This Article is brought to you for free and open access by the Natural Resources, School of at DigitalCommons@University of Nebraska - Lincoln. It has been accepted for inclusion in Papers in Natural Resources by an authorized administrator of DigitalCommons@University of Nebraska - Lincoln. 


\title{
DEVELOPMENT OF A QUALITY-ASSESSED AGRICHEMICAL DATABASE FOR MONITORING ANTHROPOGENIC IMPACTS ON GROUND-WATER QUALITY
}

\author{
MARY E. EXNER ${ }^{1, *}$, ROY F. SPALDING ${ }^{2}$ and DOROTHY M. HARRELL ${ }^{3}$ \\ ${ }^{1}$ School of Natural Resources, Institute of Agriculture and Natural Resources, University of \\ Nebraska, 306A Biochemistry Hall, Lincoln, Nebraska, U.S.A.; ${ }^{2}$ Department of Agronomy and \\ Horticulture, Institute of Agriculture and Natural Resources, University of Nebraska, Lincoln, \\ Nebraska, U.S.A.; ${ }^{3}$ Department of Agronomy and Horticulture, Institute of Agriculture and Natural \\ Resources, University of Nebraska, Lincoln, Nebraska, U.S.A. \\ (*author for correspondence, e-mail: mspalding1@unl.edu)
}

(Received 23 June 2003; accepted 31 August 2004)

\begin{abstract}
The Quality-Assessed Agrichemical Contaminant Database for Nebraska Ground Water is a unique repository of nitrate and pesticide data collected by federal, state, and local agencies. Each contaminant concentration in the database has been evaluated based upon well-defined criteria that address completeness of the well-attribute data, analytical method and field and laboratory quality control practices and assigned to one of five quality levels. The quality assessment level always accompanies the contaminant concentration so that the end-user knows the quality assurance effort expended in the acquisition of the data, can select comparable data, and choose data whose quality assurance effort is commensurate with project objectives. The database can be viewed and queried on-line; downloaded in its entirety; or imported to a spreadsheet or a geographic information system. Setting criteria for data quality and assessing the level of quality have resulted in significant increases in the percentages of high quality (Levels 3-5) nitrate and pesticide data. These high quality data presently constitute $52 \%$ of the nitrate and $55 \%$ of the pesticide data.
\end{abstract}

Keywords: database, ground water, nitrate, pesticides, water quality

\section{Introduction}

The development and implementation of state management plans (SMPs) are central to the U.S. Environmental Protection Agency's (USEPA) 1991 pesticides and ground water strategy to protect the nation's ground-water resource from pesticide contamination (USEPA, 1993). Each state has flexibility in the assessment of local ground-water vulnerability and use and in the adaptation of site-specific practices to prevent contamination that may occur from the labeled or acceptable use of pesticides and thus may pose unreasonable risk to human health and the environment. Most states have voluntarily prepared generic SMPs to facilitate the acceptance of pesticide-specific management plans (PSMPs). An EPA-approved PSMP is a requirement for the continued sale and use of each pesticide whose registration label requirement and restricted use classification, as determined by USEPA, do not 
ensure adequate protection of the ground water. Under the proposed rule, PSMPs would be required for the continued registration of atrazine, cyanazine, simazine, alachlor, and metolacholor.

States are encouraged to use existing ground-water programs and activities in the development of their SMPs and PSMPs. Both plans have the same 12 prevention, education, mitigation, and regulatory components. Developing a ground-water monitoring program, one of the 12 components, encompasses a "continuum of activities ranging from defining background conditions, to defining the existence and extent of contamination, to defining the success of prevention and response measures and programs to protect the ground water resource" (USEPA, 1993). This was a daunting challenge for Nebraska, a large (20 million ha) agricultural state with a population largely reliant on ground water for agricultural production and human consumption. In 2001 approximately 9800 tonnes of pesticide were applied to the state's 5.3 million ha of corn, soybeans, and wheat (Nebraska Agricultural Statistics Service, 2002). The PSMP-targeted herbicides atrazine, alachlor, and metolachlor comprised about one half of the pesticides applied to Nebraska soils. The 4300 tonnes of targeted herbicides were applied to 2.8 million ha of corn (U.S. Department of Agriculture, 2002). The Nebraska ground-water monitoring strategy proposed (1) to provide baseline data on the occurrence, concentration, and distribution of pesticides across the state; (2) to evaluate tends in the occurrence of PSMP pesticides; (3) to identify and evaluate problem areas; (4) to measure the success of prevention and mitigation practices and (5) to easily adapt to new information and changing circumstances (Nebraska Department of Agriculture, 1997). Timely and defensible data would be essential for a successful monitoring strategy.

In Nebraska large amounts of ground-water quality data are collected by twentythree local natural resources districts (NRDs), state and federal agencies, pesticide manufacturers, and university researchers. NRDs are charged with the conservation and development of the state's natural resources including the management of ground water. Because the agencies have different objectives, the types of wells sampled and frequency of sampling, sampling and analysis procedures, and field and laboratory quality assurance efforts vary among the entities and, depending on project goals, even within the entity. Clearly, a pesticide data clearinghouse and quality assessment of the data would preserve and organize the vast quantities of pesticide data. An advisory committee representing the state's ground-water quality data collection and dissemination groups supported the concept; and subsequently, the Nebraska Department of Agriculture and the University of Nebraska-Lincoln (UNL) agreed to collaborate and establish a comprehensive, quality-assessed pesticide database.

Intensive agriculture in Nebraska, especially corn production, requires large inputs of $\mathrm{N}$ fertilizer. Nitrate, the most frequently encountered ground-water contaminant in the state (Exner and Spalding, 1990), is the form that most concerns Nebraskans. In 2000 approximately 615400 tonnes of nitrogen fertilizer were applied 
to more than 6 million ha of corn, soybeans, and wheat (Nebraska Agricultural Statistics Service, 2002). The formation of Ground Water Management Areas (GWMAs) to protect ground water from nonpoint-source nitrate contamination is a response to a persistent problem that saw increases in nitrate concentrations as well as the extent of areal contamination prior to the formation of the earliest GWMAs. Within GWMAs natural resources districts have the authority to require producers to use best management practices and attend educational programs. With $78 \%$ of the state designated as GWMAs there has been a significant increase in nitrate monitoring. The deteriorating ground-water quality with respect to nitrate prompted the advisory committee to unanimously endorse the inclusion of nitrate data in the quality-assessed database. The Nebraska Department of Environmental Quality and UNL collaborate on the database for nitrate. Thus, ground-water monitoring for the continued use of herbicides vital to Nebraska agriculture and for assessment of nitrate contamination prompted unique collaboration among federal, state, and local agencies in Nebraska to establish a quality-assessed agrichemical contaminant database for ground water.

The clearinghouse and associated quality-assessed database organize the data collection process associated with previous ground-water quality assessments (Exner and Spalding, 1990; University of Nebraska, 1994); provide the impetus for a more coordinated and sustained data collection effort; make costly pesticide data and copious nitrate data obtained at a cost of millions of dollars readily accessible; streamline periodic assessments of the pesticide monitoring program; are invaluable in the preparation of the state-mandated annual ground-water quality monitoring report; eliminate redundancy; and ensure the judicious use of financial resources and personnel. The direction, requirements, and criteria for developing the quality-assessed database were the consensus of both the advisory committee and a technical subcommittee.

\section{Data Clearinghouse}

The objectives of the clearinghouse are (1) to enter into the database only groundwater nitrate and pesticide concentrations that reflect aquifer conditions; that is, agrichemical data that have been obtained using generally accepted field and laboratory methods and sampling locations that are documented areally, vertically, and temporally and (2) to assess the quality of the agrichemical data so that the enduser knows the quality assurance effort expended in the acquisition of the data, can select comparable data, and can choose data whose quality assurance efforts are commensurate with project objectives. To achieve these objectives five levels of criteria addressing a range of quality assurance/quality control practices were developed for seven essential data elements. Thus, the quality assessment incorporates sampling and analysis protocols (quality assurance) and the additional analyses that estimate data bias and variability (quality control). 


\subsection{QUALITY ASSESSMENT CRITERIA}

Well location, well characteristics, sampling date, sampling procedure and sample preservation, analysis method, and field and laboratory quality control practices are essential data elements that must accompany each nitrate and pesticide result submitted to the clearinghouse. The criteria for each element in each of the five quality assessment levels are shown in Tables I and II. Level 1 data meet the minimum requirements for acceptance while Level 5 data are the most defensible. The criteria addressing the location and characteristics of the well, sampling date, and sampling procedure and sample preservation are identical for both nitrate and pesticide quality assessment. The location of the well within, at most, an area of 65 ha together with the month, day, and year the sample was collected must accompany all nitrate and pesticide results. The sample must be collected using an accepted well-purging protocol. Removing three standing volumes of water, purging until temperature, $\mathrm{pH}$, and conductivity have stabilized, or monitoring until the concentration of the analyte of interest has stabilized are considered adequate for obtaining representative samples. Both the sample container and sample preservation must be as stipulated in the analytical method. While well depth and well use are required for all five quality assessment levels, Level 4 criteria require the depth(s) of the well screen(s) while Level 5 criteria are reserved for monitoring wells with known well depths and screen intervals.

Field quality control (QC) includes the collection of duplicate samples and equipment blanks; however, criteria have not been established for either the frequency of collection of field duplicate samples and equipment blanks or the acceptable range of field QC sample results. Levels 3, 4, and 5 data require the analysis of field duplicates while Levels 4 and 5 data obtained from wells without dedicated pumps must be supported by the collection and analysis of equipment blanks. Levels 1 and 2 nitrate and pesticide results are not supported by the analysis of field QC samples.

The utilized test method must produce reliable and uniform results for nitrate or pesticide analytes in a water matrix. With the exception of Level 1 results, the methods must be American Public Health Association, American Society for Testing Materials, or U.S. Environmental Protection Agency approved. Levels 4 and 5 pesticide data require a gas chromatography/mass spectrometry (GC/MS) method while Level 5 nitrate and pesticide results are obtained by the best approved method that is specific for the analyte; for example, nitrate analysis that does not include nitrite and atrazine analysis using ring-labeled atrazine and GC/MS. The Level 1 criterion - not an approved method-was developed to facilitate the acceptance of the nitrate quality-assessed database by a few NRDs using nitrate test kits. Test kit results must be verified by the frequent analysis of split samples using a standard method. Those Level 1 nitrate data meeting the laboratory quality assurance criteria are for nearly pristine ground water with very low total dissolved solids concentrations. The Level 1 pesticide method criterion accommodates 


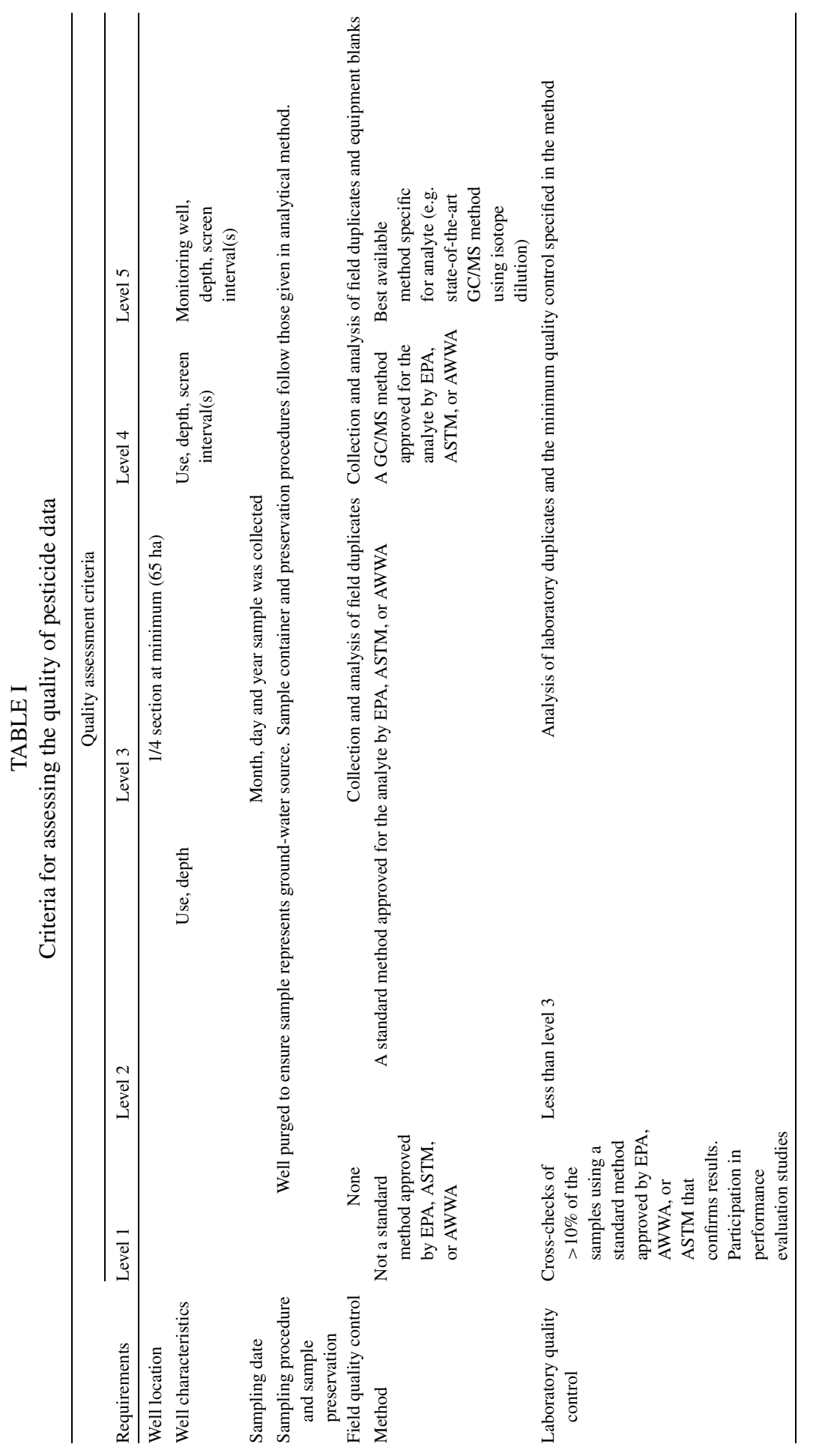


TABLE II

Criteria for assessing the quality of nitrate data

\begin{tabular}{|c|c|c|c|c|c|}
\hline \multirow[b]{2}{*}{ Requirements } & \multicolumn{5}{|c|}{ Quality assessment criteria } \\
\hline & Level 1 & Level 2 & Level 3 & Level 4 & Level 5 \\
\hline Well location & \multicolumn{5}{|c|}{$1 / 4$ section at minimum ( $65 \mathrm{ha})$} \\
\hline Well characteristics & \multicolumn{3}{|c|}{ Use, depth } & $\begin{array}{l}\text { Use, depth, screen } \\
\text { interval(s) }\end{array}$ & $\begin{array}{l}\text { Monitoring well, } \\
\text { depth, screen } \\
\text { interval(s) }\end{array}$ \\
\hline Sampling date & \multicolumn{5}{|c|}{ Month, day and year sample was collected } \\
\hline $\begin{array}{l}\text { Sampling procedure } \\
\text { and sample } \\
\text { preservation }\end{array}$ & \multicolumn{5}{|c|}{$\begin{array}{l}\text { Well purged to ensure sample represents ground-water source. Sample container and preservation } \\
\text { procedures follow those given in analytical method }\end{array}$} \\
\hline Field quality control & None & & $\begin{array}{l}\text { Collection and } \\
\text { analysis of field } \\
\text { duplicates }\end{array}$ & \multicolumn{2}{|c|}{$\begin{array}{l}\text { Collection and analysis of field } \\
\text { duplicates and equipment blanks }\end{array}$} \\
\hline Method & $\begin{array}{l}\text { Not a standard } \\
\text { method approved } \\
\text { by EPA, ASTM, } \\
\text { or AWWA }\end{array}$ & $\begin{array}{l}\text { A standard method } \\
\text { the analyte by EPA, }\end{array}$ & $\begin{array}{l}\text { pproved for } \\
\text { ASTM, or AWWA }\end{array}$ & & $\begin{array}{l}\text { Best available } \\
\text { method } \\
\text { specific for } \\
\text { analyte }\end{array}$ \\
\hline $\begin{array}{l}\text { Laboratory quality } \\
\text { control }\end{array}$ & $\begin{array}{l}\text { Cross-checks of } \\
>10 \% \text { of the } \\
\text { samples using a } \\
\text { standard method } \\
\text { approved by EPA, } \\
\text { AWWA, or } \\
\text { ASTM that } \\
\text { confirms results. } \\
\text { Participation in } \\
\text { performance } \\
\text { evaluation studies }\end{array}$ & Less than Level 3 & $\begin{array}{l}\text { Analysis of lab } \\
\text { duplicates, } \\
\text { reagent blanks, } \\
\text { fortified blanks, } \\
\text { performance } \\
\text { evaluation } \\
\text { samples }\end{array}$ & \multicolumn{2}{|c|}{$\begin{array}{l}\text { Analysis of lab duplicates, } \\
\text { reagent blanks, fortified blanks, } \\
\text { performance evaluation samples, } \\
\text { lab fortified matrix samples }\end{array}$} \\
\hline
\end{tabular}

the potential development of field test kits for individual pesticides. Because they are not pesticide-specific, immunoassay results have so far been deemed unacceptable.

Different laboratory QC criteria have been established for nitrate and pesticide data (Tables I and II). Less QC is required for Level 2 than Level 3 nitrate data. The Level 3 criterion includes the analysis of laboratory duplicates, reagent blanks, fortified blanks, and performance evaluation samples. The addition of laboratory fortified matrix samples to the laboratory QC qualifies the nitrate data for Level 4 or 5. Quality control samples for Levels 3, 4, and 5 pesticide data include laboratory duplicates and the minimum QC specified in the method. Pesticide results with less stringent laboratory QC would qualify for Level 2.

Nitrate and pesticide data received by the clearinghouse are reviewed to ensure they are accompanied by the necessary supporting data. Quality assurance plans from the submitting agency and laboratory methods are examined with respect to the quality assessment criteria. Using the established criteria (Tables I and II) each nitrate and pesticide result is assigned a quality level. In the database the concentration and quality assessment level always accompany each other and cannot be separated. 


\section{Agrichemical Database}

Ease of use, wide-ranging compatibility with other systems and software, and the ability to easily perform complex queries were of the utmost importance in designing the agrichemical database. Created in Microsoft Access, three subject-specific tables-well attributes, analyte, and submitting agency-linked together by common fields form the database (Figure 1). The well attributes table contains specific information about each sampled well. The foundation of this table is the Nebraska Department of Natural Resources (DNR) Registered Groundwater Wells Database (2003) that contains the location (federal township and range system, county, and natural resources district), use, depth, screen interval(s), completion date, and registration and sequence number of more than 139000 wells. All irrigation wells and domestic and livestock wells drilled since 1993 must be registered. With the exception of screen intervals which are not usually available in electronic format, the information is downloaded to the well attributes table and each well, whether operational or abandoned, is assigned a unique clearinghouse number that identifies the well within the database. Unregistered wells and analyte data unaccompanied by a well registration number and whose well location and pedigree cannot be convincingly tied to a registered well are assigned a clearinghouse number and the

\begin{tabular}{|c|c|c|}
\hline Well Attributes & & Analyte \\
\hline $\begin{array}{l}\text { Clearinghouse number } \\
\text { DNR registration number } \\
\text { DNR sequence number } \\
\text { Location } \\
\quad \text { longitude, latitude } \\
\quad \text { federal township \& range system } \\
\text { natural resources district } \\
\text { county } \\
\text { Depth } \\
\text { Screen interval(s) } \\
\text { Well use } \\
\text { Completion date } \\
\text { System sample } \\
\text { Agency identifiers } \\
\quad \text { (7 fields) }\end{array}$ & \begin{tabular}{|l} 
\\
One
\end{tabular} & $\begin{array}{l}\rightarrow \text { Clearinghouse number } \\
\text { Sample identification } \\
\text { Sample date } \\
\text { Analyte } \\
\text { Analyte concentration } \\
\text { Quality assessment level } \\
\text { Reporting limit } \\
\rightarrow \text { Submitting agency abbreviation }\end{array}$ \\
\hline
\end{tabular}

Figure 1. Three-table database structure with the content of each table. 
necessary information is entered into the well attributes table. While most samples are obtained from single wells, occasionally two or more wells are plumbed together and the wells cannot be sampled individually. The system sample field identifies such situations. The table also accommodates other agencies' identification nomenclature for the well.

The clearinghouse number links the well attributes table and the analyte table in a one to many relationship (Figure 1). For each sampling date the analyte table lists the analyte, its concentration and quality assessment level, analytical reporting limit, sample identification, and submitting agency. Pesticides are identified by their common name. The agency table, linked to the analyte table in a one to many relationship, contains contact information about the submitting agency.

The database is available on the World Wide Web (http://nrent3dnr.state. ne.us/clearinghouse/index.asp) through the Nebraska Department of Natural Resources website. The entire database can be downloaded or simple, efficient queries of very specific subsets can be made on-line. For example, one of several search criteria (county, NRD, well location, submitting agency, or clearinghouse or registration number) can be selected for one or more analytes. The query can be refined by defining the range of quality assessment levels, sample dates, well depths, and well types. The results are viewed either as a spreadsheet or web page table, or they can be imported to spreadsheets and converted to most database formats including dBase, Paradox, or text/comma delimited ASCII. The query results also are easily imported into a geographic information system with the capability of selecting the GIS projection. The database is updated quarterly. Links to other websites facilitate obtaining the common name for a pesticide trade name and provide information on federal drinking water regulations and health advisories.

Assessing the data quality using the five levels of criteria, essentially ranking the data, has improved the quality of the submitted data. In the five years (1998-2002) since the implementation of the quality assessment criteria, data collected by natural resources districts have shown the most dramatic improvement. Their high quality (Levels 3, 4, and 5) nitrate and pesticide data increased 31 and 19\%, respectively, from the previous five year period (1993-1997). Their acceptance of the quality assessment criteria and willingness to adopt better quality assurance practices and laboratory methodologies are extremely important as natural resources districts are projected to assume an increasingly larger role in the acquisition of ground-water nitrate and pesticide data. Between 1998 and 2002 their monitoring programs contributed $91 \%$ of the nitrate and $74 \%$ of the pesticide data in the database.

\section{Conclusion}

The Nebraska agrichemical database contains approximately 167000 qualityassessed pesticide and nitrate records for approximately 17000 wells. Since the implementation of the quality assessment criteria, the amounts of high quality 
(Levels 3, 4, and 5) nitrate and pesticide data have increased 34 and 22\% respectively. High quality data comprise 52 and $55 \%$ of the nitrate and pesticide databases, respectively. Most natural resources districts are enthusiastic about producing high quality data and the commensurate quality assessment level is a source of pride for these local agencies that in the past often lacked guidance as to good field quality assurance practices and analytical laboratory selection.

The uniqueness and reliability of the agrichemical contaminant database has earned it the only link to a state water quality database on U.S. Geological Survey's (2003) Water Quality Information website (http://water.usgs.gov/owq/hot.html).

\section{Acknowledgments}

The clearinghouse and database receive financial support from the Nebraska Departments of Agriculture and Environmental Quality. The enthusiasm and cooperation of the 23 natural resources districts is appreciated. A contribution of the University of Nebraska Agricultural Research Division, Lincoln, NE 68583. Journal Series No. 14130.

\section{References}

Exner, M. E. and Spalding, R.F.: 1990, Occurrence of Pesticides and Nitrate in Nebraska's Ground Water, Water Center Publication WC1, University of Nebraska, Lincoln, NE.

Nebraska Agricultural Statistics Service: 2002, Nebraska Agricultural Statistics Service, Lincoln, NE.

Nebraska Department of Agriculture: 1997, Nebraska Pesticides and Groundwater Generic State Management Plan, Lincoln, NE.

Nebraska Department of Natural Resources: 2003, Registered Groundwater Wells Data Retrieval, (On-line), URL: http://dnrserver26.dnr.state.ne.us/wells/wellsindex.asp.

University of Nebraska: 1994, Assessment of Pesticide Occurrence in Nebraska Ground Water, Contract Report to the Nebraska Department of Agriculture, Lincoln, NE.

U. S. Department of Agriculture: 2002, Agricultural Chemical Usage 2001 Field Crops Summary, National Agricultural Statistics Service, Washington, DC.

U. S. Environmental Protection Agency: 1993, Guidance for Pesticides and Ground Water State Management Plans, EPA 735-B-93-005a, Washington, DC.

U. S. Geological Survey: 2003, Water Quality Information Data, (On-line), URL: http://water.usgs. gov/owq/hot.html. 